\title{
Влияние гамма-облучения на фотолюминесценцию пористого кремния
}

\author{
() М.А. Елистратова ${ }^{1,2}$, Н.М. Романов ${ }^{1,3}$, Д.Н. Горячев ${ }^{2}$, И.Б. Захарова ${ }^{1}$, О.М. Сресели ${ }^{2}$ \\ ${ }^{1}$ Санкт-Петербургский политехнический университет Петра Великого, \\ 195251 Санкт-Петербург, Россия \\ ${ }^{2}$ Физико-технический институт им. А.Ф. Иоффе Российской академии наук, \\ 194021 Санкт-Петербург, Россия \\ ${ }^{3}$ Lappeenranta University of Technology, \\ 53850 Lappeenranta, Finland \\ E-mail: Marina.Elistratova@mail.ioffe.ru
}

(Получена 16 октября 2016 г. Принята к печати 21 ноября 2016 г.)

Исследовано влияние гамма-облучения на люминесцентные свойства пористого кремния, полученного электрохимическим методом. Регистрировались изменения фотолюминесценции между дозами облучения и в течение нескольких дней после последнего облучения. Обнаружено гашение фотолюминесценции при небольших дозах облучения и восстановление ее после дальнейшего облучения. Выявлено сильное окисление пористого кремния после гамма-облучения, продолжающееся в течение нескольких дней после облучения. Предполагается, что изменение спектров и интенсивности фотолюминесценции пористого кремния после гамма-облучения обусловлено изменением типа пассивации пористой поверхности: вместо водородной пассивации наблюдается более стабильная кислородная. Для стабилизации спектров фотолюминесценции пористого кремния предложено использовать фуллерен. У образца пористого кремния со слоем термически напыленного фуллерена не обнаружено значительных изменений спектров фотолюминесценции во время облучения и в течение 18 дней после него. Показана стабильность к гамма-облучению и окислению образцов пористого кремния с напыленным слоем $\mathrm{C}_{60}$.

DOI: 10.21883/FTP.2017.04.44343.8451

\section{1. Введение}

В последнее время пористый кремний активно используется в электронике и оптоэлектронике в качестве ориентирующих подложек для роста различных наноструктур $[1,2]$, как широкозонный материал для комплементарных металлооксидных полупроводниковых технологий (CMOS-технологий) [3], для фотодетекторов [4] и солнечных элементов [5], для одномерных фотонных кристаллов [6,7], химических и биологических сенсоров [8] и т.д. Такие приборы находят применение в различных отраслях промышленности, в том числе в военной, космической технике и атомной энергетике, где они могут подвергаться воздействию ионизирующего излучения. Дефекты, возникающие в CMOS-структурах на кремнии под воздействием жесткого ионизирующего облучения, приводят к частичному или полному отказу аппаратуры вследствие окисления кремния после образования дефектов и потери его свойств [9]. По этой причине изучение радиационной стабильности пористого кремния и методов защиты его от окисления являются важными темами исследования.

Вместе с тем влияние $\gamma$-излучения на свойства пористого кремния изучено недостаточно, и имеющиеся экспериментальные данные противоречивы. Имеются данные, показывающие, что под действием $\gamma$-облучения существенно изменяются структурные характеристики [10], электрические и оптические свойства [11] пористого кремния. Недостаточно ясным является вопрос о влиянии $\gamma$-облучения на фотолюминесценцию (ФЛ) этого материала. В различных работах $[12,13]$ отмечается как увеличение, так и уменьшение интенсивности ФЛ; отмечались также различные изменения формы спектров ФЛ - смещение как в „красную“, так и в „голубую“ сторону. Анализ литературных данных существенно затруднен тем, что дозы и условия облучения (на воздухе, в вакууме) у различных авторов существенно различаются. Однако все авторы отмечают сильное влияние $\gamma$-облучения на свойства пористого кремния (por-Si), поэтому вопрос стабильности свойств por-Si под действием облучения остается актуальным до сих пор.

В данной работе проведено систематическое изучение изменения фотолюминесцентных свойств пористого кремния (в частности, спектральные характеристики времяразрешенной ФЛ) под действием ряда доз $\gamma$-излучения, также регистрировались изменения во времени после последнего облучения.

Сделана попытка стабилизировать ФЛ por-Si путем нанесения на поверхность por-Si пленки фуллерена $\mathrm{C}_{60}$, который способен полимеризоваться под действием радиационного облучения $[14,15]$. Известно, что полимеризация стабилизирует свойства фуллерена [16], однако и не облученный фуллерен $\mathrm{C}_{60}$ ослабляет деградацию por-Si, например, под действием мощного лазерного излучения [17].

\section{2. Методы получения и исследования образцов}

Образцы пористого кремния были получены стандартной электрохимической методикой на подложках 
$n^{+}$-кремния при воздействии красным светом, плотность тока $10 \mathrm{MA} / \mathrm{cm}^{2}$, время травления 20-30 мин. Полученные образцы делились на две группы - состаренные, с окисленной поверхностью вследствие длительного пребывания на воздухе, и обновленные, прошедшие операцию удаления оксидов. Для снятия оксида образцы выдерживались в растворе плавиковой кислоты и спирта в пропорции 1/1 в течение 30 мин. Источником $\gamma$-лучей служил ${ }^{137} \mathrm{Cs}$, энергия квантов 661 кэВ. Облучение проводилось в атмосфере сухого кислорода, который озонировался под действием $\gamma$-облучения. Облучение было разбито на три дозы, между которыми измерялась ФЛ образцов: после первой дозы, равной (по $\left.\mathrm{H}_{2} \mathrm{O}\right) 8 \cdot 10^{5}$ Гр, после второй $1.8 \cdot 10^{6}$ Гр и после третьей $2.5 \cdot 10^{6} \Gamma \mathrm{p}$ (приведены суммарные дозы).

Спектры ФЛ измерялись в импульсном режиме при длине волны возбуждения $\lambda_{\mathrm{ex}}=337$ нм. Времяразрешенные спектры ФЛ измерялись с использованием фотоумножителя ФЭУ-79 и стробоскопического преобразователя напряжения В9-5. Регистрировалась как „быстрая“ ФЛ (в максимуме импульса возбуждения), так и „медленная“ ФЛ (квазистационарный режим) - при задержках $\sim 1$ мкс и больше между приходом лазерного импульса и моментом регистрации импульса ФЛ. Преимущество времяразрешенных спектров заключается в возможности выделения вклада так называемой „быстрой“ коротковолновой $(400-500$ нм) составляющей ФЛ [18]. Эту ФЛ обычно объясняют излучательной рекомбинацией через уровни на границе раздела por-Si и оксида кремния, и она в некоторой степени служит индикатором степени окисления поверхности por-Si.

\section{3. Полученные результаты и их обсуждение}

\section{1. Облучение пористого кремния}

После первой дозы облучения интенсивность квазистационарной ФЛ всех образцов уменьшается почти на порядок, а максимум интенсивности смещается в длинноволновую область на $\sim 30$ нм (рис. $1, a$ и $b$ ). Последующие дозы облучения приводят к возрастанию ФЛ вплоть до превышения исходных ее значений. Ослабление ФЛ большинство авторов приписывают возникновению точечных дефектов в por-Si, увеличивающих безызлучательную рекомбинацию возбужденных носителей. Наши результаты не могут быть объяснены такими эффектами, так как дозы, после которых ФЛ деградирует, обычно очень большие - например, в работе [13] они на 3 порядка больше. При этом деградация наступает после того, как при меньших дозах ФЛ растет [19]. Можно было бы предположить частичное удаление водородной пассивации во время первого облучения, но тогда неясно, почему ФЛ возрастает после следующих облучений.

Мы предположили, что в нашем случае происходит замена водородной пассивации por-Si кислородной, и для подтверждения этой гипотезы исследовали времяразрешенные спектры ФЛ. На рис. 2, $a, b$ показаны изменения
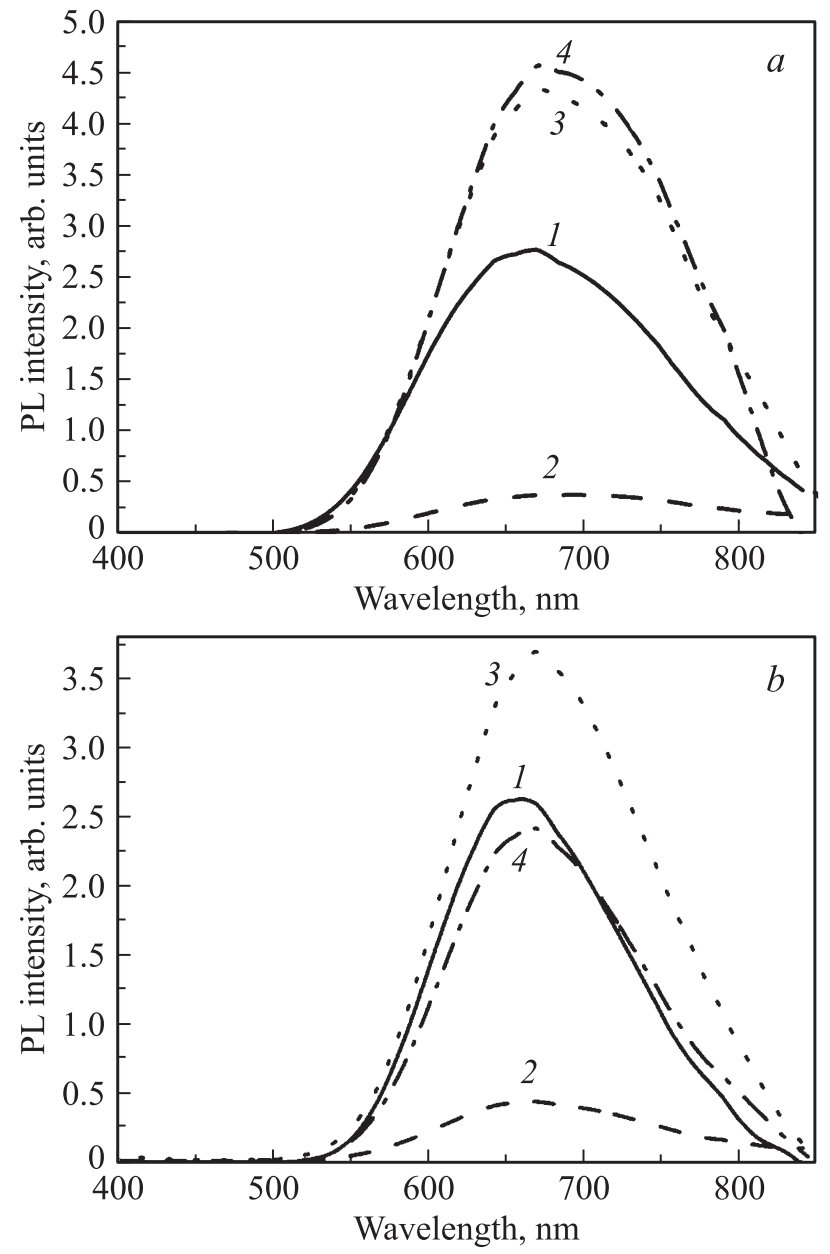

Рис. 1. Квазистационарные спектры ФЛ состаренного $(a)$ и обновленного $(b)$ образцов: до облучения $(1)$, после первой дозы (2), после двух доз (3), после трех доз $\gamma$-облучения (4).

быстрой ФЛ. Видно, что исходно присутствующая в спектре состаренного образца коротковолновая полоса после первого облучения пропадает, но восстанавливается после второй и третьей доз. Еще ярче связь оксида в por-Si с быстрой полосой ФЛ видна в спектре обновленного образца (рис. 2,b): после снятия оксида коротковолновая часть спектра пропадает, ее нет и после первой дозы, но после второй и третьей она восстанавливается, причем становится больше, чем была до снятия оксида.

Все эти данные свидетельствуют о появлении оксида и увеличении его количества в процессе облучения. Измерения „быстрой“ ${ }^{\circ}$ ФЛ образцов, хранящихся на воздухе в течение 2 недель, показаны на рис. 3. Видно, как продолжает расти интенсивность коротковолновой части спектра быстрой ФЛ, и только через 8-10 дней этот рост прекращается и наблюдается стабилизация спектра ФЛ.

Мы предполагаем, что после первой дозы облучения происходит не только генерация точечных дефектов, но также частичная эффузия водорода и превращение 

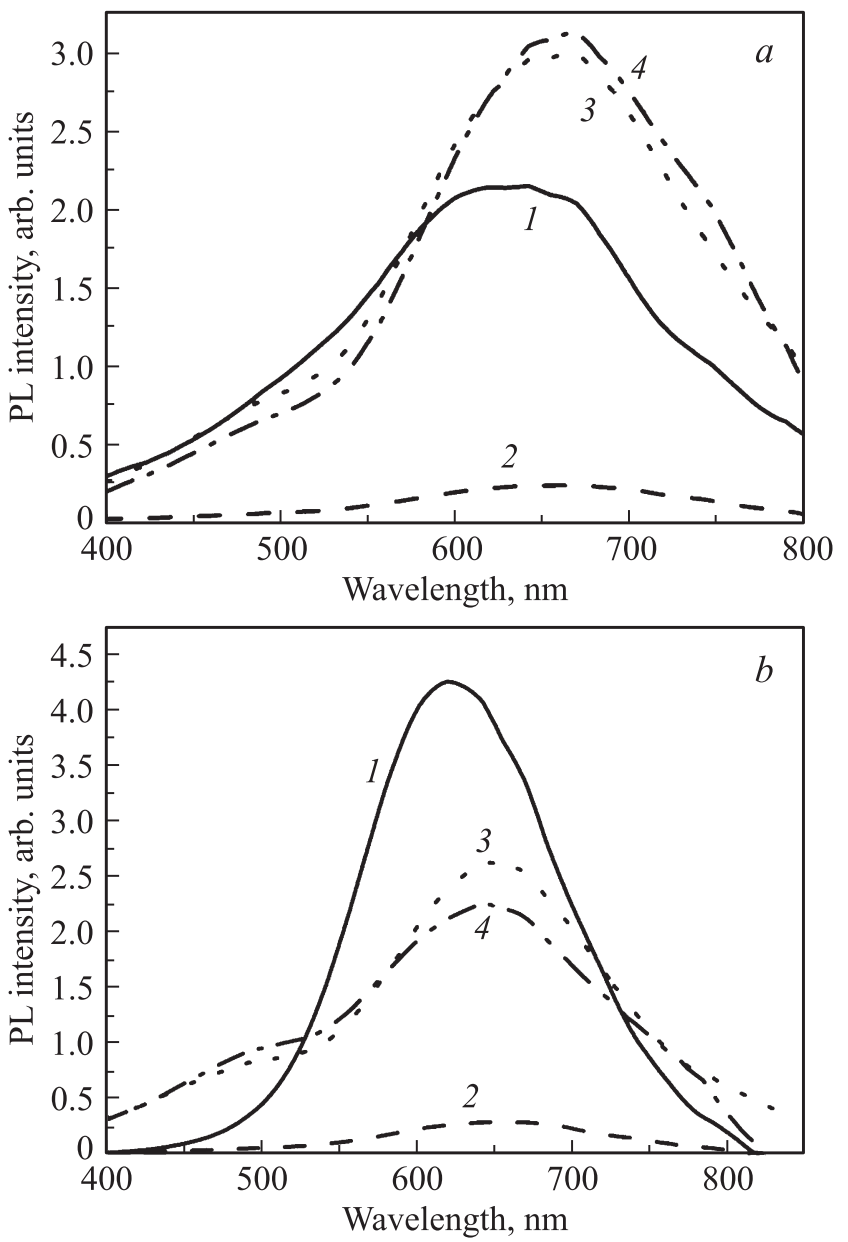

Рис. 2. Спектры „быстрой“ ФЛ состаренного (a) и обновленного (b) образцов: до облучения (1), после первой дозы (2), после двух доз (3), после трех доз $\gamma$-облучения (4).

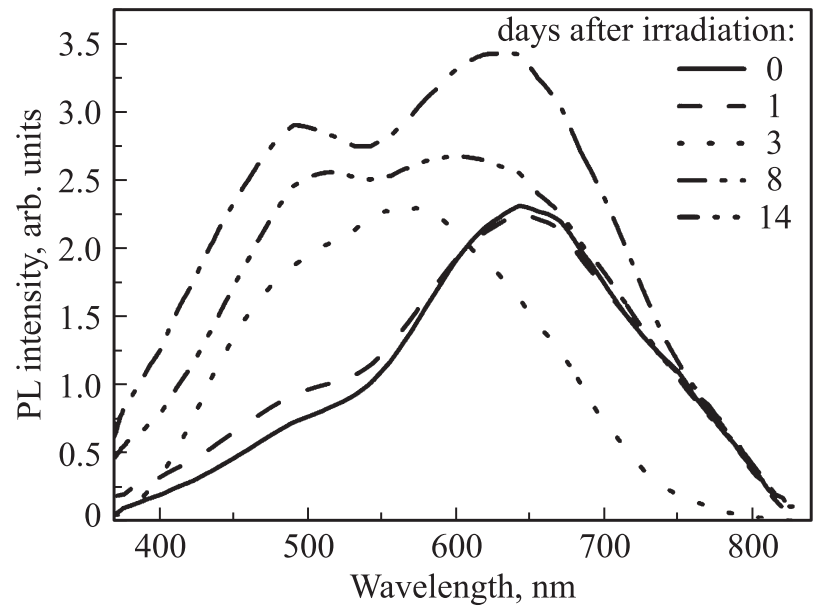

Рис. 3. Спектры „быстрой“ ФЛ обновленного образца в течение 14 дней после облучения.

радиационных центров, обусловливающих быструю коротковолновую ФЛ, в безызлучательные. Однако $\gamma$-облучение не только разрушает por-Si (возникающие дефек- ты, по-видимому, полностью разрушают самые мелкие кристаллиты por-Si, что приводит к длинноволновому сдвигу максимума спектра после первой дозы), но и стимулирует окисление por-Si, так как облучение проводится в присутствии кислорода и озона. Точечные дефекты постепенно залечиваются, а уровни на границе раздела por-Si-оксид становятся излучательными. Окисление обеспечивает кислородную пассивацию por-Si, и интенсивность ФЛ растет, постепенно приходя к насыщению.

\section{2. Облучение пористого кремния с фуллереном}

Нанесение фуллерена на поверхность пористого кремния осуществлялось двумя методами: методом полива из раствора в толуоле и последующего высушивания на воздухе (толщина слоя незначительна, видны образования из отдельных кристаллитов) и метод термического напыления в вакууме [20] (толщины напыленных слоев составляли 375-405 нм). Результаты для всех покрытых фуллереном образцов показывают снижение интенсивности ФЛ из-за поглощения фуллереном как возбуждающего ФЛ света, так и самой ФЛ пористого кремния.

Данные, полученные после нанесения фуллерена $\mathrm{C}_{60}$ методом полива, свидетельствуют о существенном окислении por-Si одновременно с нанесением $\mathrm{C}_{60}$ (рис. 4, $a$, кривые 1,2) - спектры быстрой ФЛ обладают значительный коротковолновой ФЛ. Кроме того, появляется и пик в области 740-780 нм, обусловленный ФЛ $\mathrm{C}_{60}[21]$.

Характерно отсутствие деградации ФЛ после первой дозы $\gamma$-облучения. Наблюдается только усиление коротковолнового участка спектра. Судя по всему, влияние $\gamma$-облучения на спектры сильно окисленного por-Si требует отдельного изучения самого оксида кремния под действием облучения. Усиление быстрой ФЛ после следующих доз свидетельствует о том, что пленка $\mathrm{C}_{60}$, нанесенная из раствора, - не сплошная, вследствие чего окисление por-Si продолжается.

Термическое напыление пленки $\mathrm{C}_{60}$ [21] на образец por-Si сразу после снятия оксида (рис. 4,b) понижает интенсивность ФЛ, по-видимому, из-за большой толщины пленки. В спектре быстрой ФЛ практически полностью отсутствует коротковолновая часть спектра и очень существенным становится пик ФЛ $\mathrm{C}_{60}$ в области 740-780 нм. Под действием облучения (после первой и второй доз - $\left.1.8 \cdot 10^{6} \Gamma \mathrm{p}\right)$ спектр практически не меняется и только после третьей дозы ФЛ возрастает, причем во всей области спектра.

Периодические в течение 18 дней измерения спектров образца por-Si c напыленным $\mathrm{C}_{60}$ не обнаружили значительных (превышающих обычный разброс данных) изменений квазистационарных спектров ФЛ, а спектры быстрой ФЛ изменяются только в области ФЛ фуллерена (рис. $4, b)$.

Таким образом, в случае напыления пленки фуллерена на por-Si спектры ФЛ стабилизируются, и об- 

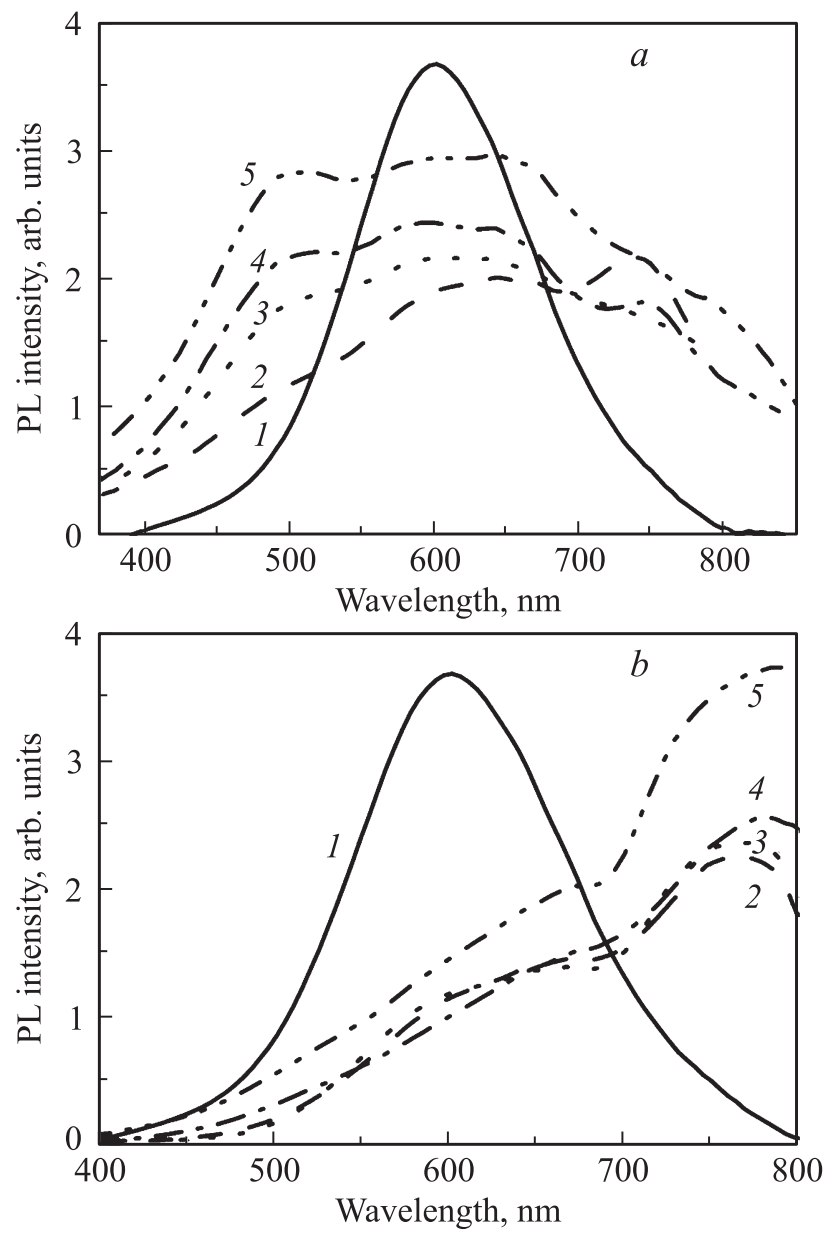

Рис. 4. Спектры „быстрой“ ФЛ обновленных образцов со слоем фуллерена $\mathrm{C}_{60}$, нанесенного из раствора $(a)$ и напылением $(b): 1$ - до нанесения $\mathrm{C}_{60}, 2$ - после нанесения $\mathrm{C}_{60}$, 3 - после первой дозы, 4 - после двух доз, 5 - после трех доз $\gamma$-облучения.

разцы не подвержены влиянию $\gamma$-облучения вплоть до доз $1.8 \cdot 10^{6} \Gamma \mathrm{p}$, при этом отсутствуют также изменения спектров, обусловленные окислением поверхности por-Si.

\section{4. Заключение}

Показано, что $\gamma$-облучение por-Si приводит к двум эффектам - окислению поверхности por-Si, обусловленному облучением в атмосфере частично озонированного сухого кислорода, и сильному гашению ФЛ после облучения дозой $8 \cdot 10^{5} \Gamma$ p. Дальнейшее облучение por-Si до $2.5 \cdot 10^{6}$ Гр увеличивает интенсивность ФЛ вплоть до значений, превышающих исходные.

Для стабилизации фотолюминесценции por-Si при $\gamma$-облучении на его поверхность наносился слой фуллерена $\mathrm{C}_{60}$ двумя способами: из раствора и термическим напылением. В обоих случаях гашение ФЛ после дозы $8 \cdot 10^{5}$ Гр пропадает. При этом в случае нанесения $\mathrm{C}_{60}$ из раствора происходит значительное окисление поверхности por-Si. При напылении $\mathrm{C}_{60}$ ФЛ остается неизменной вплоть до дозы $1.8 \cdot 10^{6} \Gamma \mathrm{p}$.

Сделан вывод, что для стабилизации свойств por-Si при $\gamma$-облучении до $\sim 1.8 \cdot 10^{6} \Gamma \mathrm{p}$ рекомендуется нанесение сплошной пленки фуллерена $\mathrm{C}_{60}$, полученной методом термического напыления.

\section{Список литературы}

[1] Н.С. Савкина, В.В. Ратников, А.Ю. Рогачев, В.Б. Шуман, А.С. Трегубова, А.А. Волкова. ФТП, 36 (7), 812 (2002).

[2] J.I. Sohn, S. Lee, Y.H. Song, S.Y. Choi, K.I. Cho, K.S. Nam. Appl. Phys. Lett., 78 (7), 901 (2001).

[3] С.К. Лазарук, А.А. Лешок, В.А. Лабунов, В.Е. Борисенко. ФТП, 39 (1), 149 (2005).

[4] N. Naderi, M.R. Hashim. J. Alloys Comp., 552, 356 (2013).

[5] J.H. Petermann, D. Zielke, J. Schmidt, F. Haase, E.G. Rojas, R. Brendel. Prog. Photovolt.: Res. Appl., 20 (1), 1 (2012).

[6] J.O. Estevez, V. Agarwal. Porous Silicon Photonic Crystals. Handbook of Porous Silicon (Springer Intern. Publ., 2014) p. 805.

[7] A. Birner, R.B. Wehrspohn, U.M. Gösele, K. Busch. Adv. Mater., 13 (6), 377 (2001).

[8] V.S.Y. Lin, K. Motesharei, K.P.S. Dancil, M.J. Sailor, M.R. Ghadiri. Science, 278 (5339), 840 (1997).

[9] T.R. Oldham, F.B. McLean. IEEE Trans. Nucl. Phys., 50 (3), 483 (2003).

[10] I.K. Abbas, L.A. Najam, A.U.K.A. Sulaiman. Int. J. Phys., 3 (1), 1 (2015).

[11] L.A. Najam, I.K. Abbas, A.U.K. A. Sulaiman. Adv. Appl. Sci. Res., 5, 218 (2014).

[12] J.S. Fu, J.C. Mao, E. Wu, Y.Q. Jia, B.R. Zhang, L.Z. Zhang, Y.H. Zhang. Appl. Phys. Lett., 63 (13), 1830 (1993).

[13] Е.В. Астрова, В.В. Емцев, А.А. Лебедев, Д.И. Полоскин, А.Д. Ременюк, Ю.В. Рудь, В.Е. Харциев. ФТП, 29 (7), 1301 (1995).

[14] F. Cataldo. Fullerene Sci. Technol., 8 (6), 577 (2000).

[15] H. Klesper, R. Baumann, J. Bargon, J. Hormes, H. ZumaquéDíaz, G.A. Kohring. Appl. Phys. A, 80 (7), 1469 (2005).

[16] Т.Л. Макарова. ФТП, 35 (3), 257 (2001).

[17] О.М. Сресели, Д.Н. Горячев, Л.В. Беляков, С.П. Вуль, И.Б. Захарова, Е.А. Алексеева. ФТП, 38 (1), 124 (2004).

[18] A.G. Cullis, L.T. Canham, P.D.J. Calcott. J. Appl. Phys., 82 (3), 909 (1997).

[19] Е.В. Астрова, Р.Ф. Витман, В.В. Емцев, А.А. Лебедев, Д.С. Полоскин, А.Д. Ременюк, Ю.В. Рудь. ФТП, 30 (3), 507 (1996).

[20] J. Drechsel, H. Fröb. Vakuum in Forschung und Praxis (Wiley, 2008), 20 (S1), 15 (2008).

[21] И.Б. Захарова, В.М. Зиминов, Н.М. Романов, О.Е. Квятковский, Т.Л. Макарова. ФТТ, 56 (5), 1024 (2014).

Редактор Л.В. Шаронова 
The effect of gamma irradiation on porous silicon photoluminescence

M.A. Elistratova ${ }^{\mathbf{1}, 2}$, N.M. Romanov ${ }^{\mathbf{1 , 3}}$,

D.N. Goryachev ${ }^{2}$, I.B. Zakharova ${ }^{1}$, O.M. Sreseli ${ }^{2}$

${ }^{1}$ Peter the Great St. Petersburg Polytechnic University, 195251 St. Petersburg, Russia

2 loffe Institute,

194021 St. Petersburg, Russia

${ }^{3}$ Lappeenranta University of Technology,

53850 Lappeenranta, Finland

Abstract Photoluminescent properties of porous silicon subjected to a series of gamma-radiation doses were investigated in present work. Porous silicon was obtained by commonly used electrochemical etching. Photoluminescence changes after each radiation dose and during some days after the last dose were registered. Photoluminescence quenching at a low irradiation dose and photoluminescence recovery after subsequent radiation were found. After gamma-irradiation strong oxidation of porous silicon was observed, which persisted for some days. The effects were supposed to be caused by the changes of porous-silicon passivation. Instead of the hydrogen passivation, the more stable oxygen passivation appeared after gamma-irradiation. It was proposed to use fullerene for stabilization of the photoluminescence spectra. There were no significant changes in the photoluminescence of the sample with evaporated $\mathrm{C}_{60}$ layer during irradiation and in 18 days after that. Stability of the porous silicon with the deposited $\mathrm{C}_{60}$ layer to gamma-irradiation and oxidation was shown. 